\title{
Analysis of the genetic diversity of physic nut, Jatropha curcas L. accessions using RAPD markers.
}

\begin{abstract}
A sum of 48 accessions of physic nut, Jatropha curcas L. were analyzed to determine the genetic diversity and association between geographical origin using RAPD-PCR markers. Eight primers generated a total of 92 fragments with an average of 11.5 amplicons per primer. Polymorphism percentages of J. curcas accessions for Selangor, Kelantan, and Terengganu states were 80.4, 50.0, and 58.7\%, respectively, with an average of $63.04 \%$. Jaccard's genetic similarity co-efficient indicated the high level of genetic variation among the accessions which ranged between 0.06 and 0.81. According to UPGMA dendrogram, 48 J. curcas accessions were grouped into four major clusters at coefficient level 0.3 and accessions from same and near states or regions were found to be grouped together according to their geographical origin. Coefficient of genetic differentiation (Gst) value of J. curcas revealed that it is an outcrossing species.
\end{abstract}

Keyword: Genetic diversity; Jatropha curcas; RAPD_PCR; Geographic origin. 